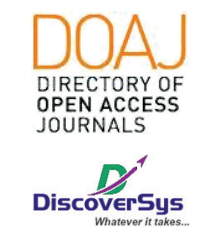

Published by DiscoverSys

\section{Determinan Perilaku perawatan kesehatan gigi dan mulut pada anak usia 12 tahun di wilayah kerja Puskesmas I Baturiti}

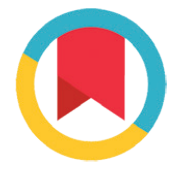

CrossMark

\author{
Ni Nyoman Feby Wulandari, ${ }^{,}$Steffano Aditya Handoko, Desak Putu Yuli Kurniati
}

\title{
ABSTRACT
}

Introduction: Dental and oral health is a fundamental part of general health and affects the overall well-being. Experts agree that dental and oral diseases are "behavioral diseases" or diseases related to behavior. Factors that affects the behavior of dental and oral health care is yet unknown, which leads to a research that involving 12 years old children in Puskesmas I Baturiti, Tabanan, to see the most affect the determinants to the behavior of oral hygiene.

Method: Study design using cross sectional analytic model involving on 12 years old children in the working area of Puskesmas I Baturiti, Tabanan. All sample were taken using simple random sampling. Chisquare test was used to determine the association between knowledge, information support, attitudes, parental support, and teacher support towards oral hygiene behavior.
Result: The study shows that correlation between health determinants with oral hygiene behavior on children age 12 years old, based on the knowledge, the result is $p=0.007$. The result also shows that based on attitude, $p=0.033$, and when based on the source of information, $p=$ 0.000 . Lastly, the result based on parental support and teacher support are $p=0.028$, and $p=0.009$.

Conclusion: There is a significant correlation between knowledge, attitude, source of information, parental and teacher support with treatment behavior of oral hygiene in children. Source of information is the dominant factors that affect the behavior of oral hygiene in children age 12 years old in Puskesmas I Baturiti, Tabanan.

Keywords: oral hygiene behavior, resources, children age 12 years old. Cite This Article:Wulandari, N.N.F., Handoko, S.A., Kurniati, D.P.Y. 2018. Determinan Perilaku perawatan kesehatan gigi dan mulut pada anak usia 12 tahun di wilayah kerja Puskesmas I Baturiti. Intisari Sains Medis 9(3): 55-58. D0I: 10.1556/ism.v9i3.265

\section{ABSTRAK}

Latar Belakang: Kesehatan gigi dan mulut merupakan bagian fundamental dari kesehatan umum dan berpengaruh terhadap kesejahteraan secara keseluruhan. Para ahli sepakat bahwa penyakit gigi dan mulut merupakan "behavioral disease" atau penyakit terkait perilaku. Faktor yang mempengaruhi perilaku perawatan kesehatan gigi dan mulut belum diketahui, sehingga perlu dilakukan penelitian untuk melihat determinan yang paling berpengaruh terhadap perilaku perawatan kesehatan gigi dan mulut pada anak usia 12 tahun di wilayah kerja Puskesmas I Baturiti, Tabanan.

Metode: Penelitian ini menggunakan desain cross sectional analitik. Sampel pada penelitian ini adalah anak sekolah dasar yang berusia 12 tahun yang berada di wilayah kerja Puskesmas I Baturiti, Tabanan tahun ajaran 2016 dengan teknik simple random sampling.
Hasil: Penelitian ini menunjukkan hasil hubungan determinan dengan perilaku perawatan kesehatan gigi dan mulut pada anak usia 12 tahun berdasarkan pengetahuan yaitu $p=0,007$. Berdasarkan sikap dengan nilai $p=0,033$. Berdasarkan sumber informasi yaitu $p=0,000$. Berdasarkan dukungan orang tua yaitu $p=0,028$. Sedangkan berdasarkan dukungan guru diperoleh $p=0,009$.

Simpulan: Adanya hubungan yang signifikan antara pengetahuan, sikap, sumber informasi, dukungan orang tua dan dukungan guru dan sekolah dengan perilaku perawatan kesehatan gigi dan mulut pada anak. Sumber Informasi merupakan faktor dominan dalam mempengaruhi perilaku perawatan kesehatan gigi dan mulut pada anak usia 12 tahun di wilayah kerja Puskesmas I Baturiti, Tabanan.
Program Studi Pendidikan Dokter Gigi, Fakultas Kedokteran, Universitas Udayana.

*Corresponding:

Ni Nyoman Feby Wulandari, Program Studi Pendidikan Dokter Gigi,

Fakultas Kedokteran, Universitas

Udayana

feby.wulandari@gmail.com

Diterima: 2018-05-08

Disetujui: 2018-09-14

Diterbitkan: 2018-12-1
Kata kunci : perilaku perawatan gigi dan mulut, sumber informasi, anak usia 12 tahun

Cite This Article:Wulandari, N.N.F., Handoko, S.A., Kurniati, D.P.Y. 2018. Determinan Perilaku perawatan kesehatan gigi dan mulut pada anak usia 12 tahun di wilayah kerja Puskesmas I Baturiti. Intisari Sains Medis 9(3): 55-58. D0I: 10.1556/ism.v9i3.265

\section{PENDAHULUAN}

Kesehatan gigi dan mulut merupakan bagian fundamental dari kesehatan umum dan berpengaruh terhadap kesejahteraan secara keseluruhan. Memiliki kesehatan gigi dan mulut yang optimal dapat membantu seseorang untuk mempertahankan fungsi oralnya, serta dapat membuat seseorang merasa lebih 
baik dan percaya diri. ${ }^{1}$ Kesehatan gigi dan mulut ini dianggap sangat penting karena rongga mulut merupakan tempat yang sangat ideal bagi perkembangan bakteri, jika gigi dan mulut tidak dibersihkan dengan baik, maka sisa-sisa makanan yang terselip bersama bakteri akan bertambah banyak dan akan membentuk plak. Plak ini merupakan tempat pertumbuhan ideal bagi bakteri Streptococcus mutans dan Lactobacillus spp yang nantinya akan memfermentasikan substrat karbohidrat dan menghasilkan asam organik. Asam ini menyebabkan $\mathrm{pH}$ menurun dan mengakibatkan demineralisasi pada jaringan gigi yang mengakibatkan terjadinya karies atau yang sering disebut gigi berlubang. ${ }^{2}$

Di Indonesia, penyakit gigi dan mulut termasuk dalam sepuluh besar penyakit terbanyak di pusat pelayanan kesehatan primer (Puskesmas), dengan proporsi nasional sebesar $25,9 \%$, dan karies gigi merupakan penyakit gigi dan mulut yang paling sering terjadi dibandingkan dengan penyakit gigi dan mulut lainnya, seperti gingivitis dan periodontitis. ${ }^{3}$ Karies dapat terjadi pada berbagai kelompok usia, tetapi paling rentan menyerang anak usia 6-12 tahun. Menurut WHO (2013), anak usia 12 tahun merupakan kelompok penting, karena pada usia ini semua gigi permanen telah tumbuh, kecuali gigi molar 3, dan kesehatan gigi dan mulut harus sangat dijaga untuk mencegah terjadinya penyakit gigi dan mulut pada gigi permanen yang telah tumbuh.

Berdasarkan data Riset Kesehatan Dasar Provinsi Bali tahun 2013, sebanyak 22,4\% anak usia $10-14$ tahun mengalami permasalahan gigi dan mulut dalam 12 bulan terakhir, dengan indeks Decay Missing FilledTeeth (DMF-T) mencapai 4,1\%. Tingginya angka DMF-T, dapat terjadi akibat perilaku perawatan kesehatan gigi dan mulut yang buruk. ${ }^{4}$

Para ahli sepakat bahwa penyakit gigi dan mulut merupakan "behavioral disease" atau penyakit terkait perilaku. Derajat kesehatan gigi dan mulut yang prima adalah cerminan pengalaman perilaku perawatan gigi dan mulut yang baik. Menurut penelitian yang dilakukan Smyth dkk, (2007) di Spanyol pada siswa usia 12 tahun, menemukan bahwa anak dengan pengetahuan yang lebih baik cenderung memiliki sikap dan perilaku yang lebih baik terkait perawatan kesehatan gigi dan mulut dibandingkan anak dengan pengetahuan kurang. ${ }^{5}$

Dari hasil data survei pendahuluan yang telah dilakukan di Puskesmas I Baturiti, Tabanan, diketahui bahwa $42 \%$ anak menderita gigi berlubang. Sedangkan prevalensi nasional karies gigi menurut data Riskesdas 2013 adalah 25,9\%, hal ini menunjukkan bahwa prevalensi karies gigi di daerah ini cukup tinggi, di mana karies merupakan penyakit yang paling sering terjadi pada anak dan dapat terjadi akibat perilaku perawatan kesehatan gigi dan mulut yang buruk. Sehingga tujuan dari penelitian ini adalah untuk melihat determinan yang berpengaruh terhadap perilaku perawatan kesehatan gigi dan mulut pada anak usia 12 tahun di wilayah kerja Puskesmas I Baturiti, Tabanan.

\section{METODE PENELITIAN}

Jenis penelitian ini menggunakan pendekatan cross sectional analitik untuk mengetahui hubungan antara variabel bebas dengan variabel tergantung. Sampel pada penelitian ini adalah anak sekolah dasar yang berusia 12 tahun yang berada di wilayah kerja Puskesmas I Baturiti, Tabanan tahun ajaran 2016. Desain pengambilan sampel yang digunakan adalah cluster sampling untuk sekolah dasarnya yang berjumlah 23, di wilayah kerja Puskesmas I, Baturiti, Tabanan, dengan asumsi rata-rata jumlah siswa kelas VI adalah 25 orang. Dari 23 sekolah dasar ini, peneliti membutuhkan 92 orang siswa, maka dari itu peneliti mengambil 5 sekolah dasar. Pemilihan cluster dengan cara simple random sampling, dilanjutkan dengan penentuan sampel.

Pengumpulan data pada penelitian ini dilakukan dengan menggunakan kuisioner. Kuesioner yang diberikan berisi daftar pertanyaan yang mengacu pada konsep dan teori sesuai dengan uraian pada tinjauan pustaka. Pertanyaan dalam kuisioner terdiri dari 7 sub pertanyaan yaitu terdiri dari karakteristik responden, perilaku perawatan kesehatan gigi dan mulut, pengetahuan mengenai perilaku perawatan kesehatan gigi dan mulut, sikap, sumber informasi, dukungan orang tua serta dukungan guru dan sekolah. Adapun penilaian dalam kuisioner dilihat dari persentase jawaban tertinggi reponden pada masing-masing sub pertanyaan. Analisis data dalam penelitian ini menggunakan uji chi-square, analisis resiko dengan menghitung nilai odds ratio, dan binary logistic regression untuk mencari variabel yang paling berperan terhadap perilaku kesehatan gigi dan mulut.

\section{HASIL PENELITIAN}

Penelitian ini menggunakan rancangan cross-sectional yang melibatkan 112 anak sekolah dasar di wilayak kerja Puskesmas I Baturiti Tabanan. Melalui analisis chi-square didapatkan adanya hubungan yang bermakna antara pengetahuan, sikap, sumber informasi, dukungan orang tua, dan dukungan guru dan sekolah terhadap perilaku kesehatan gigi dan mulut $(\mathrm{p}<0,05)$ (Tabel 1). Melalui analisis regresi logistik didapatkan hanya pengetahuan dan sumber informasi yang berpengaruh terhadap perilaku menjaga kesehatan gigi dan mulut, serta hal yang paling berperan dalam perilaku menjaga kesehatan gigi dan mulut adalah sumber informasi ( $<<0,05$; adjusted OR: 7,412) (Tabel 2). 
Tabel 1 Tabulasi silang pengetahuan, sikap, sumber informasi, dukungan orang tua, dukungan guru dengan perilaku perawatan kesehatan gigi dan mulut

\begin{tabular}{|c|c|c|c|c|}
\hline \multirow[b]{2}{*}{ Karakteristik } & \multicolumn{2}{|c|}{ Perilaku } & \multirow[b]{2}{*}{ OR (IK 95\%) } & \multirow[b]{2}{*}{$p$} \\
\hline & Kurang (\%) & Baik (\%) & & \\
\hline \multicolumn{5}{|l|}{ Pengetahuan } \\
\hline Kurang & $32(50 \%)$ & $32(50 \%)$ & 3.00 & $0,007^{*}$ \\
\hline Baik & $12(25 \%)$ & $36(75 \%)$ & $(1,32-6,78)$ & \\
\hline \multicolumn{5}{|l|}{ Sikap } \\
\hline Kurang & $18(54,5 \%)$ & $15(45,5 \%)$ & 2,44 & $0,033^{*}$ \\
\hline Baik & $26(32,9 \%)$ & $53(67,1 \%)$ & $(1,06-5,61)$ & \\
\hline \multicolumn{5}{|c|}{ Sumber Informasi } \\
\hline Tidak ada & $12(85,7 \%)$ & $2(14,3 \%)$ & 12,37 & $0,000^{*}$ \\
\hline Ada & $32(32,7 \%)$ & $66(67,3 \%)$ & $(2,61-58,61)$ & \\
\hline \multicolumn{5}{|c|}{ Dukungan Orang Tua } \\
\hline Kurang & $30(48,8 \%)$ & $32(51,6 \%)$ & 2,41 & $0,028^{\star}$ \\
\hline Baik & $14(28 \%)$ & $36(72 \%)$ & $(1,09-5,23)$ & \\
\hline \multicolumn{5}{|c|}{ Dukungan Guru dan Sekolah } \\
\hline Kurang & $23(54,8 \%)$ & $19(45,2 \%)$ & 2,82 & $0,009^{*}$ \\
\hline Baik & $21(30 \%)$ & $49(70 \%)$ & $(1,27-6,24)$ & \\
\hline
\end{tabular}

${ }^{*}$ Analisis chi-square, signifikan $\mathrm{p}<0,05$

Tabel 2 Hasil pemodelan regresi logistik

\begin{tabular}{lcccc}
\hline & & & \multicolumn{2}{c}{ IK 95\% } \\
\cline { 4 - 5 } Variabel & $\boldsymbol{p}$ & adjusted OR & Atas & Bawah \\
\hline Pengetahuan & $0,019^{*}$ & 2,828 & 7,630 \\
Sumber Informasi & $0,015^{*}$ & 7,412 & 37,214 \\
Dukungan Orang Tua & 0,091 & 2,192 & 5,452 \\
Dukungan Guru dan Sekolah & 0,085 & 2,226 & 5,538 \\
\hline
\end{tabular}

${ }^{*}$ Analisis Regresi Logistik, signifikan $\mathrm{p}<0,05$

\section{PEMBAHASAN}

Berdasarkan data dari Tabel 1 diperoleh bahwa sebanyak $36(75 \%)$ anak yang memiliki perilaku baik mempunyai pengetahuan yang baik sedangkan diantara yang berpengetahuan baik ada 12 (25\%) anak yang memiliki perilaku yang kurang. Hasil analisis yang diperoleh menunjukkan bahwa nilai $\mathrm{p}<0,05$ artinya ada hubungan yang signifikan antara pengetahuan dengan perilaku perawatan kesehatan gigi dan mulut pada anak usia 12 tahun di wilayah kerja Puskesmas I Baturiti, Tabanan. Dalam penelitian ini, tingkat pengetahuan responden mengenai kunjungan rutin setiap 6 bulan sekali ke dokter gigi tergolong tinggi, yaitu 92,9\%, namun dari seluruh responden hanya 15,2\% yang selalu rajin berkunjung ke dokter gigi setiap 6 bulan sekali. Ini juga didukung oleh penelitian yang dilakukan oleh Carneiro L, dkk (2011) yang sudah mendapatkan hasil berupa tingkat pengetahuan anak-anak usia sekolah dasar di Tanzania mengenai kesehatan gigi. Hasil yang didapatkan tergolong tinggi, yakni 91,3\% sampel telah memiliki pengetahuan yang adekuat mengenai karies gigi, namun dari seluruh sampel tersebut, hanya $2,4 \%$ yang menyikat gigi dengan interval 12 jam dan 39,9\% yang mengunjungi dokter gigi secara berkala. ${ }^{6}$ Sebenarnya pemeriksaan rutin setiap 6 bulan sekali telah dianjurkan oleh Persatuan Dokter Gigi Indonesia (2006), pemeriksaan rutin ke dokter gigi sangat dianjurkan pada anak usia sekolah, karena pada anak usia sekolah telah mengalami pergantian gigi susu menjadi gigi permanen). ${ }^{7}$

Berdasarkan data Tabel 1 diperoleh bahwa sebanyak $53(67,1 \%)$ anak memiliki sikap yang baik dengan perilaku yang baik, sedangkan di antara yang memiliki sikap yang baik ada $26(32,9 \%)$ anak yang berperilaku kurang. Hasil analisis yang diperoleh menunjukkan bahwa nilai $\mathrm{p}<0,05$ artinya ada hubungan antara sikap dengan perilaku perawatan kesehatan gigi dan mulut pada anak usia 12 tahun di wilayah kerja Puskesmas I Baturiti, Tabanan. Hasil penelitian ini juga didukung oleh penelitian yang dilakukan Applonia, dkk (2014), bahwa pengetahuan dan sikap terhadap kesehatan gigi berpengaruh secara signifikan terhadap perilaku pemeliharaan kebersihan gigi dan mulut ibu hamil sebesar $41,6 \%$ dan selebihnya $58,4 \%$ ditentukan oleh variabel di luar penelitian ini. ${ }^{8}$

Berdasarkan data Tabel 1 diperoleh bahwa ada sebanyak $66(67,3 \%)$ anak mendapatkan sumber informasi dengan perilaku yang baik. Sedangkan di antara anak yang mendapatkan sumber informasi, ada 32 (32,7\%) anakyang berperilaku kurang dengan $\mathrm{p}<0,05$ artinya ada hubungan yang signifikan antara sumber informasi dengan perilaku perawatan kesehatan gigi dan mulut pada anak usia 12 tahun di wilayah kerja Puskesmas I Baturiti, Tabanan. Hasil penelitian ini juga didukung oleh penelitian yang dilakukan Rahmawati (2007), menemukan adanya peningkatan yang signifikan terhadap perilaku ibu balita setelah diberikan penyuluhan dengan media audio visual, hal ini disebabkan semua media sebenarnya berguna untuk memperjelas, menimbulkan kesan mendalam, artinya apa yang disuluhkan tidak mudah dilupakan oleh responden. ${ }^{9}$

Berdasarkan data dari Tabel 1 diperoleh bahwa ada sebanyak $36(72 \%)$ anak yang mendapatkan dukungan dari orang tua yang baik dengan perilaku yang baik. Sedangkan di antara anak yang mendapatkan dukungan dari orang tua yang baik ada 14 (28\%) anak yang berperilaku kurang. Hasil analisis yang diperoleh menunjukkan bahwa nilai $\mathrm{p}<0.05$ artinya ada hubungan yang signifikan. Hasil penelitian ini juga didukung oleh beberapa penelitian yang terangkum dalam sebuah systematic riview menunjukkan bahwa kehadiran dukungan 
orang tua akan mempermudah perawatan gigi dan mulut oleh dokter gigi dengan perilaku positif yang diberikan oleh anak. Hal ini dikarenakan anak akan bersikap dan berperilaku lebih patuh terhadap tindakan yang dilakukan dokter gigi mengingat adanya kepercayaan yang diberikan pada anak oleh orang tua bahwa tindakan perawatan gigi yang dilakukan tidak akan menyakiti anak tersebut. ${ }^{10}$

Berdasarkan data dari Tabel 1 diperoleh bahwa sebanyak 49 (70\%) anak dengan dukungan dari guru dan sekolah yang baik memiliki perilaku yang baik. Sedangkan di antara anak dengan dukungan dari guru dan sekolah yang baik, ada 21 (30\%) anak yang berperilaku kurang. Hasil analisis yang diperoleh menunjukkan bahwa nilai $\mathrm{p}<0.05$ artinya ada hubungan yang signifikan. Hasil penelitin ini juga didukung oleh penelitian yang dilakukan oleh Nadia, dkk (2012) menyatakan bahwa terdapat hubungan yang bermakna antara pelaksanaan program UKS oleh sekolah dengan perilaku hidup bersih dan sehat. Menggosok gigi yang baik adalah setelah makan pagi dan malam hari sebelum tidur. Maka dari itu sebaiknya sekolah menyediakan tempat untuk menggosok gigi, sehingga para siswa bisa menggosok gigi mereka setelah makan pada jam istirahat di sekolah. ${ }^{11-14}$

Berdasarkan hasil analisis regresi logistik (Tabel 2) yang dilakukan pada seluruh variabel bebas, ditemukan bahwa variabel bebas yang paling berhubungan dengan perilaku perawatan kesehatan gigi dan mulut pada anak usia 12 tahun di wilayah kerja Puskesmas I Baturiti, Tabanan adalah sumber informasi, dengan nilai signifikan 0.015, nilai $\mathrm{p}<0,05$ dan nilai $O R$ tertinggi yaitu sebesar 7,41 (95\% IK: 1,47-37,21), yang artinya anak yang mendapatkan sumber informasi memiliki perilaku 7,41 kali lebih baik dibandingkan dengan anak yang tidak mendapatkan sumber informasi mengenai perawatan kesehatan gigi dan mulut. Hal ini juga didukung penelitian yang dilakukan oleh Alfarista, dkk (2013) yang menunjukkan bahwa ada hubungan yang bermakna antara sumber informasi dengan perilaku seksual berisiko remaja di Kecamatan Sumbersari Kabupaten Jember. ${ }^{13}$

\section{SIMPULAN}

Perilaku perawatan kesehatan gigi dan mulut pada anak usia 12 tahun di wilayah kerja Puskesmas I Baturiti, Tabanan cukup baik. Determinan yang berhubungan dengan perilaku perawatan kesehatan gigi dan mulut adalah pengetahuan, sikap, sumber informasi, dukungan orang tua, dukungan guru dan sekolah. Berdasarkan ketiga faktor tersebut, yang paling berhubungan dengan perawatan kesehatan gigi dan mulut pada anak usia 12 tahun di wilayah kerja Puskesmas I Baturiti, Tabanan adalah sumber informasi

\section{SARAN}

Bagi pihak sekolah agar ke depannya merencakan program UKGS di sekolah masing-masing, dan agar pihak sekolah juga menyediakan tempat untuk menggosok gigi bagi anak-anak agar setelah jam istirahat mereka bisa menggosok gigi mereka setelah makan. Pertahankan juga penempelan poster-poster bertema kesehatan di lingkungan sekolah.

\section{DAFTAR PUSTAKA}

1. Al Subait AA, et al. Oral health knowledge, attitude and behavior among students of age 10-18 years old attending Jenadriyah festival Riyadh; a cross-sectional study. The Saudi Journal for Dental Research. 2016;7(3):45-50.

2. Featherstone, J. D. B. Dental Caries: A Dynamic Disease Process. Australian Dental Journal. 2008;53(3):286-291.

3. Mikail B, Candra A. 90 Persen Anak SD di Bangka Sakit Gigi. http://health.kompas.com./read/2011/09/20/09005592/90. Persen.Anak.SD.di.Bangka.Sakit.Gigi. 2011.

4. Kementrian Kesehatan RI. Riset Kesehatan Dasar Dalam Angka (Riskesdas 2013) Provinsi Bali. Cetakan Pertama. Lembaga Penerbitan Badan Litbangkes. Jakarta. 2013.

5. Smyth E, Caamaño F, \& Fernández RP. Oral health knowledge, attitudes and practice in 12-year-old schoolchildren. Med Oral Patol Oral Cir Bucal. 2007;12(8):614-20.

6. Carneir L, et al. Oral health knowledge and practices of secondary school students, tanga, Tanzania, International Journal of Dentistry. 2011;2(1):1-6.

7. Hockenberry MJ, Wilson D. Wong's nursing care infants and children. St. Louis: Mosby Elsevier. 2007.

8. Applonia. PB, Widyanti N. Faktor-faktor yang mempengaruhi perilaku pemeliharaan kebersihan gigi dan mulut ibu hamil di puskesmas kabupaten kupang. Maj Ked Gi. 2014;21(1):20-26.

9. Rahmawati, Ira. Sudargo, Toto. Paramastri. Ira. Pengaruh Penyuluhan dengan media Audio Visual terhadap Peningkatan Pengetahuan Sikap dan perilaku Ibu Balita Gizi Kurang dan Buruk di kabupaten Kotawaringin barat Provinsi Kalimantan Selatan. Jurnal Gizi Klinik Indonesia. 2007;4(2):69-77.

10. Suprabha BS, Arathi Rao. Role of parent behavior guidance of children in dental operatory: curent trends. International Journal of Advanced Research. 2015;3(1):466-70.

11. Nadia SR, Nurdin Y. Hubungan pelaksanaan program usaha kesehatan sekolah terhadap perilaku hidup bersih dan sehat pada siswa sdn 13 seberang padang utara. Ners Jurnal Keperawatan. 2012;8(2):196-201.

12. Rahardjo A. et al. Measurement of Tooth Brushing Frequency, Time, and Duration of Adults and Children in Jakarta Indonesia. Journl of Dentistry Indonesia. 2014;21(3): 85-88.

13. Alfarista A, Dina A. Hubungan Sumber Informasi Dengan Perilaku Seksual Berisiko Remaja di Kecamatan Sumbersari Kabupaten Jember. 2014.

14. Lely Suratri, M., N, I., Setiawaty, V. Correlation between dental health maintenance behavior with Dental Caries Status (DMF-T). Bali Medical Journal 7(1): 56-60. 2018. DOI:10.15562/bmj.v7i1.836

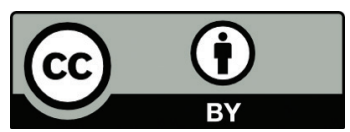

This work is licensed under a Creative Commons Attribution 